\title{
Analysis of the Communication Levels of the Students Studying in Music Education and Preschool Education in Terms of Music and Different Variables
}

\author{
Arzu Gülbahçe ${ }^{1}$, Taner Çalmaşur ${ }^{2}$, Erdoğan Tozoğlu ${ }^{3}$ \\ 1 Atatürk University, Kazım Karabekir Education Faculty Music Education Department, Erzurum/Türkiye \\ 2Atatürk University, Faculty of Education, Department of guidance and psychological counseling, Erzurum/Türkiye \\ 3Atatürk University, Kazım Karabekir Education Faculty, Erzurum/Türkiye \\ Correspondence: Arzu Gülbahçe, Atatürk University, Kazım Karabekir Education Faculty Music Education Department, \\ Erzurum/Türkiye.
}

Received: March 2, 2019

Accepted: March 20, 2019

Online Published: March 21, 2019

doi:10.11114/jets.v7i3S.4163

URL: https://doi.org/10.11114/jets.v7i3S.4163

\begin{abstract}
The aim of this study was to investigate the communication levels of the students who are studying in music education and preschool education in terms of music and different variables. The universe of the research is composed of students studying in the music education and preschool Department of Ataturk University Kazım Karabekir Faculty of Education in 2017-2018 academic year. The sample group consists of 237 people, 128 women and 109 men, who were educated in music education and preschool education.

In this study, "communication skills inventory" developed by ersanlı and balci (1998) was used to investigate the communication levels of students. (Ersanl1, K.) and Balci, S. (1998). The data were analyzed using the SPSS 21 package program and ANOVA Waryans tests were applied to examine the frequency distribution for distribution of demographic variables of the participants, the relationship between two independent variables and communication levels, and the relationship between two independent variables and communication level. The difference between variables p.0,05 was interpreted taking into account the significance level.
\end{abstract}

According to the findings, there was a significant difference between the students ' communication levels and gender, family structure, The type of music they are listening to, the average listening time per week, the use of musical instrument and the duration of use per week. The communication levels of female students were higher than those of male students and the communication levels of the students in the fragmented family structure were higher than those in the other family structure. It is also important to note that the communication levels of students increase as their weekly listening time increases, and the use of the music instrument has a positive effect on the communication level. It was observed that the students who used 1 hour and six musical instruments in the Weekly environment had a high level of communication between the students who did not use the musical instrument and who used it in different periods. It was observed that the communication points of the students who listen to art music and rock music are higher than the students who listen to other types of music.

It was determined that there was no significant difference between the communication levels of the students and the age, the Department of Education and the meanings expressed by music. Although there was no significant difference between the variables, it was observed that the communication level of the students aged 22 and above was higher than the students aged 21 .

As a result of the data obtained from the research, it was concluded that the duration of listening to music, using a musical instrument and the type of music they are listening to have a positive effect on the communication levels of the students. In the context of the results, students are encouraged to use any musical instrument in line with their listening and listening skills and to provide the necessary facilities. It is recommended that music education and preschool teachers, especially at different levels of Education, be aware that music has a positive effect on communication which is important in the development of children and in expressing themselves, and that they direct children to different social and cultural activities related to music.

Keywords: communication, music, university student 


\section{Introduction}

Since human beings are social beings, they try to make sense of their environment by communicating with other people. Because different social environments in which human beings exist consist of relationships between other people. People who relate to each other both inform others about themselves and collect information from the other side. For this reason, the need for self-expression and understanding of others in the nature of man has pushed individuals to communicate (Cüceloğlu, 1995).

Communication, Information, ideas, feelings, attitudes, etc. it is the Exchange and transfer of images that are reconciled with the channels used as a result of the relationships between the source and the recipients of blood behavior ( Yüksel, 2010). In terms of meaning, it is the process in which the factors that lead to the formation of our culture with our feelings, thoughts, ideas and knowledge are expressed through symbols (tutur,2003). "Communication is communication from a certain Center to society" (Güngör, 2011). Communication, knowledge, skills, emotions, thoughts, attitudes and attitudes are defined as the process of sharing or co-ordinating meanings (Bolat, 1990). According to dökmen (1994), communication is the process of Exchanging Messages between two units, in other words, generating, transferring and meaning. Communication is expressed as a process of bringing the message issuer closer to each other in the fields of creating and sharing information, both through intermediaries and without them (Bektaş, 2002).

Music; joy, sadness, etc. it is an important tool in expressing emotions, recognizing different cultures, and communicating socially and culturally, but it is a cultural resource and a scientific research area(Babacan, 2011). Music, feelings, thoughts, impressions and designs, and other facts with the contribution of certain situations, facts and events, a certain purpose and method, according to a certain understanding of beauty by combining, processing and explaining with formatted sounds is an aesthetic whole. It is the only language that everyone can understand and understand (uçan, 2005). Music is considered as one of the most effective and important tools that should be used in the education of All children and it is seen as an important tool that affects the language development, emotional and social development of children positively (canakay, 2006; yıldız, 2002).

Individuals with advanced communication skills can cope with the problems they face in their lives in a more healthy way, develop satisfying relationships and become more successful in their social lives. On the other hand, their ability to adapt to the society in which they live depends on their ability to solve the problems in the most appropriate way (Cüceloğlu, 2003). The acquisition of this skill in the socialization and education of the individual is very effective in the success of the future life. Therefore, care is taken to gain communication skills in educational levels. Communication skills that are replaced by teaching curricula are a skill that must be acquired and used effectively in all disciplines (Durukan, maden, 2010).

\section{Methods}

\subsection{Materials and Methods}

This section describes the research method and pattern used in the research, the universe and its sample, data collection tools, data collection process and data analysis techniques. The communication skills assessment scale (IBD) was used in the study. Communication skills assessment scale (IAP): a 5-scale likert scale developed to understand how individuals evaluate their communication skills, IAP consists of 25 expressions. The scale, which was rated in $0-4$ format in 1996 by korkut, was structured to be rated in 1-5 format in 1997. The excess of the points obtained from the scale without the opposite substances means that individuals evaluate their own communication skills in a positive way. The validity and reliability of the scale were made by the same person and the alpha internal consistency coefficient was 0.80 . In statistical analysis, significance level was chosen as $\mathrm{p}<0.05$. In the research, the survey technique, which is frequently used in the survey method, was used as data gathering technique.

\subsection{Data Collection Techniques}

In the research, the data collection tool consists of two parts.

In the first part, "personal information form" developed by the researcher was used to obtain the personal information of the students who completed the survey, which includes the variables of the department, gender, age, family structure, musical instrument usage and musical listening status.

In the second part, Korkut (1997) used the 'communication skills assessment scale'. The assessment scale for communication skills is a 25 -point scale. The scale is prepared in the type of 5 liquor.

\subsection{Data Analysis}

Data collected SPSS 21. the results were analyzed and interpreted in the package program. In the analysis of data, frequency distribution in determining the demographic characteristics, $t$ test was applied to examine the relationship 
between two independent variables and communication skills, and test was applied to examine the relationship between two variables and communication skills. Significance level p. 0,05 taken.

\section{Results}

In this section, frequency distributions for the demographic characteristics of the participants and their musical listening and usage situations are presented. T test and anowa analysis test results are presented for the students involved in the study.

Table 1. Demographic Characteristics Of The Students Involved In The Study

\begin{tabular}{c|c|c|c}
\hline Variable & Distribution & Number $(\mathbf{N})$ & Percent (\%) \\
\hline \multirow{4}{*}{ Gender } & Man & 109 & 46,0 \\
\cline { 2 - 4 } & Woman & 128 & 54,0 \\
\cline { 2 - 4 } Old & Total & 237 & 100,0 \\
\hline \multirow{3}{*}{ Section } & 21 years and under & 111 & 53,2 \\
\cline { 2 - 4 } & 22 years and older & 126 & 55,3 \\
\cline { 2 - 4 } & Music Education & 106 & 44,7 \\
\hline \multirow{2}{*}{ Family Structure } & Preschool & 169 & 71,3 \\
\cline { 2 - 4 } & Camily-Friendly Hotel & 52 & 21,9 \\
\hline
\end{tabular}

A total of 237 samples of 109 men and 128 women, 131 from the music Department and 106 from the preschool Department, were participated.

Table 2. Distribution Of Interest Groups Of Students In The Study

\begin{tabular}{|c|c|c|c|}
\hline Variable & Distribution & Number $(\mathbf{N})$ & Percent (\%) \\
\hline Would you listen to music? & Yes & 237 & 100,0 \\
\hline \multirow{3}{*}{ Weekly Music Listening Time } & 1 hour and less than 1 hour & 22 & 9,3 \\
\hline & 2 to 4 hours & 85 & 35,9 \\
\hline & 5 hours and more & 130 & 54,9 \\
\hline \multirow{4}{*}{ What Do You Think Is Music } & All meaningful and rhythmic sounds & 18 & 7,6 \\
\hline & Transfer Of Emotions & 134 & 56,5 \\
\hline & All & 72 & 30,4 \\
\hline & A Universal Language & 13 & 5,5 \\
\hline \multirow{2}{*}{ Do you use a musical instrument? } & Yes & 144 & 60,8 \\
\hline & Nope & 93 & 39,2 \\
\hline \multirow{4}{*}{ Music Playback Time } & 1 hour and less than 1 hour & 23 & 9,7 \\
\hline & 2-4 hours & 55 & 23,2 \\
\hline & 5 hours and more & 66 & 27,8 \\
\hline & I don't use & 93 & 39,2 \\
\hline
\end{tabular}

Table 3. T values of the mean and standard deviations of the scores obtained from the communication Scale with the gender of the students and the difference between the averages.

\begin{tabular}{c|c|c|c|c|c}
\hline Gender & N & X & Ss & t & p \\
\hline Man & 109 & 92,3945 & 13,47152 & $-3,253$ & $\mathbf{, 0 0 1 *}$ \\
\hline \multirow{2}{*}{ Woman } & 128 & 97,8438 & 12,30097 & $-3,229$ \\
\hline
\end{tabular}


It was found that there was a significant difference between the scores of the students in the study and the scores obtained from the gender and communication skills scale. The communication level of female students was higher than that of male students.

Table 4. T values of the mean and standard deviations of the scores obtained from the communication Scale with the ages of the students and the difference between the averages

\begin{tabular}{c|c|c|c|c|c}
\hline Old & $\mathbf{N}$ & $\mathbf{X}$ & $\mathbf{S s}$ & $\mathbf{t}$ & $\mathbf{p}$ \\
\hline 21 years and under & 111 & 94,5676 & 11,79647 & $-3,253$ & \multirow{2}{*}{, $\mathbf{0 0 1}^{*}$} \\
\cline { 1 - 4 } 22 years and older & 126 & 96,0159 & 14,17998 & $-3,229$ & \\
\hline
\end{tabular}

It was found that there was a significant difference between the mean scores of the students who participated in the study in terms of their age and communication skills. It was found that the communication level of the students aged 22 years and above was higher than the students aged 21 years and below.

Table 5. T values of the average and standard deviations of the scores obtained from the communication scale and the departments where students are studying and the differences between the averages.

\begin{tabular}{c|c|c|c|c|c}
\hline Section & $\mathbf{N}$ & $\mathbf{X}$ & $\mathbf{S s}$ & $\mathbf{t}$ & $\mathbf{p}$ \\
\hline Music Education & 131 & 96,6031 & 11,94905 & 1,658 & \multirow{2}{*}{$\mathbf{0 0 1 *}$} \\
\hline preschool & 106 & 93,7736 & 14,32100 & 1,627 & \\
\hline
\end{tabular}

It was found that there was a significant difference between the scores of the students in the study and the scores of the communication skills scale. The communication level of the students studying in music department was higher than that of the students studying in preschool.

Table 6. The mean and standard deviations of the scores obtained from the communication scale and family structures of the students and the difference between the averages

\begin{tabular}{c|c|c|c|c|c|c}
\hline Family Structure & N & X & Ss & F & P & \\
\cline { 1 - 4 } Nuclear Family (1) & 169 & 96,1243 & 12,89527 & & & \\
\cline { 1 - 4 } Extended Family (2) & 52 & 90,9231 & 12,15883 & \multirow{2}{*}{5,121} & $\mathbf{0 0 7}$ & $\mathbf{3}<\mathbf{1 , 2}$ \\
\cline { 1 - 4 } Fragmented Family (3) & 16 & 101,3750 & 15,02831 & & & \\
\cline { 1 - 4 } Total & 237 & 95,3376 & 13,11051 & & &
\end{tabular}

It was found that there was a significant difference in the mean scores of the students in the study from the scale of family structures and communication skills. It was determined that the communication level of the students in the fragmented family structure was higher than the students in the core and large family structure.

Table 7. $T$ values of the averages and standard deviations of the scores obtained from the communication scale and the cases of students using Musical Instruments and the differences between averages

\begin{tabular}{c|c|c|c|c|c}
\hline $\begin{array}{c}\text { Do you use any musical } \\
\text { instrument (instrumental)? }\end{array}$ & $\mathbf{N}$ & $\mathbf{X}$ & Ss & $\mathbf{t}$ & $\mathbf{p}$ \\
\hline Yes & 144 & 97,8333 & 12,73616 & 3,746 & \multirow{2}{*}{, $000 *$} \\
\cline { 1 - 4 } Nope & 93 & 91,4731 & 12,80420 & 3,742 & \\
\hline
\end{tabular}

It was found that there was a significant difference between the scores of the students using any musical instrument and the communication skills scale. It was determined that the level of students who use musical instruments was higher than those who do not use musical instruments. 
Table 8. Students ' Weekly music listening times and the average of the scores received from the communication scale and standard deviations and differences between averages

\begin{tabular}{|c|c|c|c|c|c|c|}
\hline $\begin{array}{c}\text { Weekly Music Listening } \\
\text { Time }\end{array}$ & $\mathbf{N}$ & $\mathbf{X}$ & Ss & $\mathbf{F}$ & $\mathbf{P}$ & Fark \\
\hline 1 hour and less (1) & 22 & 85,8182 & 11,53313 & \multirow{4}{*}{9,916} & \multirow{4}{*}{, 000} & \multirow{4}{*}{$\begin{array}{r}1<2,3 \\
3>2\end{array}$} \\
\hline 2-4 hours (2) & 85 & 93,6824 & 9,04909 & & & \\
\hline 5 hours and more (3) & 130 & 98,0308 & 14,65994 & & & \\
\hline Total & 237 & 95,3376 & 13,11051 & & & \\
\hline
\end{tabular}

It was found that there was a significant difference between the average scores of the students in the Weekly music listening time and the communication skills scale. It was found that the communication level of the students who had 1 hour and 6 hours of listening time was lower than the students who had 2 to 4 hours of listening time and 5 hours of listening time, and the students who had 2-4 hours of listening time were lower than the students who had 5 hours of listening time However, as music listening time increases, the level of communication increases in parallel.

Table 9. Mean and standard deviation of the scores obtained from the communication scale and the meaning of Music for students and the difference between the averages.

\begin{tabular}{c|c|c|c|c|c|c}
\hline What Music Means To You & N & X & Ss & F & P & Fark \\
\hline $\begin{array}{c}\text { All expressive and rhythmic } \\
\text { sounds (1)) }\end{array}$ & 18 & 98,6111 & 12,35808 & & & \\
\cline { 1 - 4 } Transfer Of Emotions (2)) & 134 & 93,6194 & 13,94123 & \multirow{2}{*}{$\mathbf{2 8 0}$} & \multirow{2}{*021}{} & $\mathbf{1 , 3} \mathbf{2 , 4}$ \\
\cline { 1 - 4 } Everything (3)) & 72 & 98,0417 & 9,92001 & & & \\
\cline { 1 - 4 } A Universal Language (4)) & 13 & 93,5385 & 18,20080 & & & \\
\hline Total & 237 & 95,3376 & 13,11051 & & & \\
\hline
\end{tabular}

It was determined that there was a significant difference between the mean scores of the students from the communication skills scale with the meaning expressed by music. It was determined that the communication level of the students who expressed that the music was all and everything were meaningful and rhythmic sounds were higher than the students who expressed that music was a universal language and that the music was a transfer of emotions.

Table 10. Students ' average scores and standard deviations and differences between averages with weekly Musical Instrument usage times and Communication scale.

\begin{tabular}{|c|c|c|c|c|c|c|}
\hline Music Playback Time & $\mathbf{N}$ & $\mathbf{X}$ & Ss & $\mathbf{F}$ & $\mathbf{P}$ & \\
\hline 1 hour and six (1)) & 23 & 106,3043 & 11,06360 & \multirow{5}{*}{11,880} & \multirow{5}{*}{, 000} & \multirow{5}{*}{$\begin{array}{c}1>2,3,4 \\
3>2,4\end{array}$} \\
\hline 2-4 hours ( 2 hours)) & 55 & 92,8727 & 9,22367 & & & \\
\hline 5 hours and more (3)) & 66 & 99,0152 & 14,04004 & & & \\
\hline I'm not using (4)) & 93 & 91,4731 & 12,80420 & & & \\
\hline Total & 237 & 95,3376 & 13,11051 & & & \\
\hline
\end{tabular}

It was found that there was a significant difference in the mean scores between the students ' weekly musical instrument usage times and the communication skills scale (p: 05). It was found that the communication level of the students who had 1 hour and 6 were higher than the students who had 2 hours and 5 hours and above, and the students who had 5 hours and above were higher than the students who had 2 or 4 hours and those who had 2 or 4 hours and those who had not.

\section{Conclusions and Recommendations}

A total of 237 samples of 109 men and 128 women were included in the study, 131 from music Department and 106 from preschool. It was observed that all the students who participated in the study listened to music and mostly had 5 hours and more per week. It was also determined that 144 of the students used musical instruments and mostly used musical instruments for 5 hours per week. 
It was found that there was a significant difference between the scores of the students in the gender and communication skills scale, and that the communication level of the female students was higher than that of the male students. In this study, it was found that there was a significant relationship between gender and communication skills. In this study, a significant difference was found between gender and communication levels in the Faculty of Education candidates of Karabükoğlu and bayraktar (2014), and both studies supported the results.

It was found that there was a significant difference in p:,05 significance level between the students ' age and communication skills scale, and the communication level of 22 years and older students were higher than 21 years and younger students. In a study by korkut (1997) on university students, and in a study by Korkutoğlu and Bayraktar (2014) on faculty of education teachers, there was no significant difference between age and communication levels. Our study differs with these studies.

Their communication skills between family structure and Education Department students with scores taken from the scale: $p, 05$ is significantly different at significance level, fragmented family structures and extended family structure is the core of the communication level of the students in the music Department students in the level of communication the students who are studying in pre-school were higher than it was determined that the students who study in the section.

It was determined that there was a significant difference in the mean scores of the students using any musical instrument and communication skills scale, and that the level of communication of the students using music instrument was higher than the students who did not use music instrument.

Students' weekly listening to music and using musical instruments taken from the scale scores between time and communication skills: p,listening to music that is significantly different at significance level of 05 Duration 1 hour and six of the students communication level and the duration of 2-4 hours and over 5 hours of listening to the music of students who are low in students who are between 2-4 hours of music listening time and 5 hours of the students is LOW, the duration of communication using a musical instrument and six 1 hour weekly students Level 2- hours 5 hours and over, and students who do not use is higher than the duration of 5 hours weekly between the hours of 2-4 and students using a musical instrument, and it was determined that students were higher than those who do not use.

It was found that there was a significant difference between the mean scores of the communication skills scale for the students with the meaning expressed by music and the significance level of p: 05, and that the communication level of the students with the meaning and rhythm of the music was higher than the students who expressed that the music was a universal.

As a suggestion, since communication has an important influence on the exchange of information with other people in daily and professional life of individuals, it is suggested that music listening and using musical instruments are effective in improving communication skills. It is also recommended to investigate and identify different independent variables that may have a positive or negative impact on communication.

\section{References}

Açıkgöz, K. (2003). Effective learning and teaching. Izmir: Kanyılmaz.

Babacan, E. (2011). Investigation of University Students' Music Likes in terms of Different Variables, II. National Hisarlı Ahmet Symposium, 137-150.

Bektaş, A. (2002). Political Propaganda, Bağlam Publishing, Ankara.

Bolat, S. (1990). Instructor-student communication in higher education. (Unpublished master's thesis). Hacettepe University, Ankara.

Canakay, U. E. (2006). Developing Attitude Scale for Music Theory Course. National Music Education Symposium Announcement, PAU Faculty of Education, Denizli: 26-28 April.

Cüceloğlu, D. (1995). Again to Human. Istanbul: Remzi publication.

Cüceloğlu, D. (2003). Communication Equipment. Istanbul: Remzi publication.

Dökmen, Ü. (1994). Communication conflicts and empathy in art and everyday life. Istanbul: System.

Durukan, E., \& Maden, S. (2010). Journal of Social Sciences Research, 1, 59-74.

Erol, A. (2009). Understanding Popular Music Meaning in Popular Music in the Context of Cultural Identity (3rd Edition) Ankara: Bağlam Publication.

Güngör, N. (2011). Introduction: Contact: Political Publication.

Korkut, F. (1997). Evaluation of Communication Skills of University Students. IV. National Educational Sciences, Congress Proceedings. Anatolian University, 208-218, Eskişehir. 
Pehlivan, K. B. (2005). A Study on Perceptions of Teacher Candidates' Communication Skills, Elementary-Online, 4(2), $17-23$.

Raymond, W. Gibbs, Jr. Cambridge: Cambridge University Press, 502-524

Saban, A. (2008). Metaphors, Theory and Practice in School Management, 55, 459-496

Saban, A. (2009). Mental Images of Teacher Candidates on Student Concept, Turkish Journal of Educational Sciences, $7(2), 281-326$

Tozoğlu, E., \& Bayraktar, G. (2014). Effects of sports on communication skills: a research on teacher candidates. Research on Humanities and Social Sciences, 4(2), 68-74.

Uçan, A. (2005). Music Education-Basic Concepts and Principles-Approaches Situation in Turkey, Universal Müzikevi, 3rd Edition, Ankara.

Yıldız, G. (2002). Teaching Primary Education (First Level). Ankara: Anı Publishing.

Zbikowsky, L. M. (2008). Music and Metaphor, The Cambridge Handbook of Metaphor and Thought (ed).

\section{Copyrights}

Copyright for this article is retained by the author(s), with first publication rights granted to the journal.

This is an open-access article distributed under the terms and conditions of the Creative Commons Attribution license which permits unrestricted use, distribution, and reproduction in any medium, provided the original work is properly cited. 